\title{
A Proposed Framework for Knowledge Sharing in Sudanese Organizations
}

\author{
Fadwa Mohammed Al Faki \\ MSc. IT, Sudan University of \\ Science and Technology, \\ Khartoum, Sudan
}

\author{
Nisreen Beshir Osman \\ Assistant Professor, Department of \\ Computer Science, Bayan College of \\ Science and Technology, P.O. Box \\ 210 , Khartoum, Sudan
}

\author{
Mohammed A. Osman \\ Mukhtar \\ College of Computer Science \& \\ Information Technology \\ Alzaeim Alazhari University \\ Khartoum North, Sudan
}

\begin{abstract}
Knowledge Management is one of the most important strategies that organizations can use to enhance their competitive advantage. Sharing knowledge is considered to be an important area in knowledge management and one of the major challenges for Sudanese organizations due to their organizational culture that is difficult to change in order to support the process of Knowledge management. This study investigates the status of knowledge sharing in Sudanese organizations and explores the factors and requirements that influence an effective knowledge sharing process in these organizations. A questionnaire was used to collect data that investigate the state of knowledge sharing in Sudanese organizations. The collected data was analyzed, and based on the results the study proposed a framework that identified the factors that significantly influence knowledge sharing in Sudanese organizations. The framework highlighted the important roles of Management support, IT infrastructure, Organization Culture and confidence and Trust in the process of Knowledge Management implementation and Knowledge Sharing in Sudan. This study confirms that the strategy for implementing successful KM initiatives in Sudanese organizations requires precise understanding and effective management of the core knowledge infrastructures and processes and that the integration of knowledge into management decisions and practices relies on the extent to which the organizational culture supports or hinders knowledge processes.
\end{abstract}

\section{Keywords}

Knowledge Management, Knowledge Sharing; Organization Culture; Sudanese Organizations; Framework

\section{INTRODUCTION}

Knowledge is a combination of experience, culture, context information and the expert sight that provides the evaluation frame and combines the expert with new knowledge; Knowledge management is the way of exceeding the best use of available knowledge resources [1]

Knowledge Management (KM) is one of the most important strategies that organizations should provide in order to create and maintain competitive advantage. One of the important elements in KM is Knowledge Sharing (KS). KS is very challenging for Sudanese organizations due to their organizational culture that is difficult to change in order to support the process of KM. These organizations need clear guidelines for the requirements of a successful KS implementation. In addition, a framework for the application of KS towards greater efficiency, creativity, improvement and development of products and services in a world of changes and challenges are also needed.
This study investigates KS in Sudanese organizations by exploring the its current situation and identifying the main obstacles of KS implementation process, and then proposes a framework that enable Sudanese organizations adopt KS and ensure the success of KS process.

\section{BACKGROUND}

This section highlights works related to the study according to five categories: Human Knowledge, Knowledge Classification and Types, Knowledge Management, Knowledge Sharing, and Organization Culture.

\subsection{Human Knowledge}

Knowledge is an important element in human life. It became one of the most effective and influential elements in this era since it guides organizations and provides them with ways to capture, collect, organize, preserve and develop information assets that enable them to benefit in the long run [2] [3]

\subsection{Knowledge Classifications and Types}

Types of Knowledge vary according to their sources, mechanism of participation and exchange, the purpose of application and objectives, as well as the differences of views of researchers. Lundval [2] classified knowledge into four types:

- Know-why is knowledge about principles and laws

- Know-how is the skills and the ability to perform a certain task

- Know-Who is the information about who knows what or who knows how to perform

Knowledge can also be classified into two types [4] [5] [6] [7]:

Tacit Knowledge is the knowledge inherent in the minds of humans, reflected by their behavior, and expressed through personal experience, rules of reasoning, intuition, personal judgment, feeling, and social interaction.

Explicit Knowledge is existing knowledge stored in the organization's archive (policy manuals, procedures, documents, and operating standards) and can be encoded, written and transmitted to others; Explicit Individuals within the organization can often access and use them and can be shared with all staff through seminars, meetings and books.

\subsection{Knowledge Management}

Knowledge Management (KM) is the process of creating, sharing, using and managing knowledge and information of an organization [8]. It is the process of capturing, distributing, and effectively using knowledge [9]. KM is the discipline that promotes an integrated approach to identifying, capturing, 
evaluating, retrieving, and sharing all of an enterprise's information assets [3].

\subsection{Knowledge Sharing}

Knowledge Sharing (KS) means the exchange of skills, knowledge, and experiences among individuals and groups [10]. Organizations have recognized that knowledge constitutes intangible assets to create and maintain competitive advantages among knowledge participants.

Senge [11] [12] pointed out that KS is an exchange of information that happens when people are really interested in helping others to develop new skills at work, it is a creation of learning processes.

KS significantly increases people's knowledge and broadens their horizons. However, it is a major challenge in the field of knowledge management due the cultural issues such as the resistance and non motivational factors to sharing knowledge with others [13].

Ipe [14] introduced a framework for the factors that affect sharing and exchanging of knowledge of individuals. According to this model the nature of knowledge, motivation to share knowledge and the opportunty to share knowledge are integrated together to create an ideal environment for Knowledge sharing.

Jones et al. [15] also introduced a framework that targets teams working on projects thus allowing them to exchange knowledge among themselves and among the rest of the organization.

Goh [16] presented a framework for knowledge transfer which included factors such as types of knowledge, organizattions structure, and knowledge recipient among the factors the affect the effectiveness of knowledge transfer.

\subsection{Organization Culture}

Hukzinski t al. [17] describe Organizational Culture (OC) as quite monotonous set of values, beliefs, customs, traditions and stable methods transmitted by the members. Also, other has considered it as the impression of subculture of society having been formed inside industrial, trade and economic organizations [18]

According to De Long et al. [9] there is a strong link between OC and KM since OC influences behaviors and values central to KM. Nonaka et al. [20] and Zheng et al. [21] pointed out that knowledge is an outcome of OC because knowledge is created, made sense of, shared and utilized in accordance with a set of cultural values and norms embedded in structural relationships and reflected in strategic priorities. Studies [22] [23] has also shown that organizations with cultures emphasizing innovation are more likely to use KM Systems and facilitate KS through subjective norms that encourage sharing.

Alavi et al. [24] emphasized that OC is a critical element for the application of KM and its various activities and that culture the use of KMSs and the outcomes of such use. A study by Zahidul et al [25] concluded that cultural elements, namely Trust, communication between staff, and leadership are vital for KS in organizations.

\section{METHODOLOGY}

This section describes the steps of the Methodology used in this study to explore the current situation of knowledge sharing, identify the main obstacles of the knowledge sharing implementation process, and then propose the framework for ensuring a successful knowledge sharing process in Sudanese organizations. These steps are illustrated in Figure 4 below.
Investigating Sudanese organization KS status

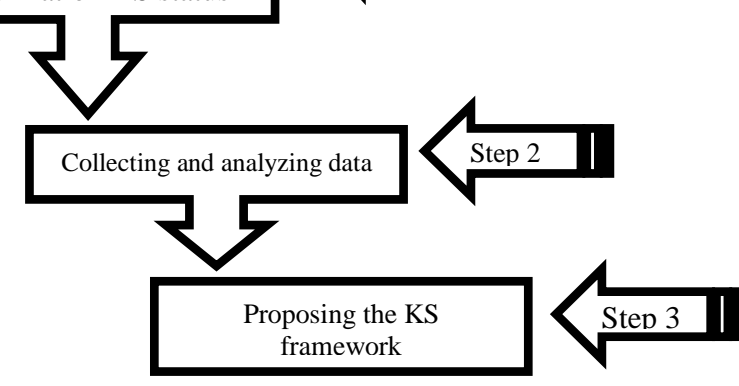

Fig1: The Steps of the Methodology

\subsection{Step One: Investigating the Status of KS in Sudanese organizations}

In order to identify the factors that impact KS in Sudanese organizations this step investigated the following

- Organization Management attitude toward Knowledge Management and sharing

- Organizational culture and cooperation between employees and senior management and within employees.

- Social relations within organizations

- Current behaviors and factors that support the process of knowledge sharing.

- IT Infrastructure and systems available to operate business in these organizations

Based on these investigation a list of requirements were developed which represents the factors that impact knowledge sharing process.

\subsection{Step Two: Collecting and Analyzing Data}

A questionnaire was used to gather data required to investigate the status of KS in Sudanese organizations. The questionnaire was distributed within ten (10) different organizations with different specialties within governmental and private sectors. From each organization 10 staffs were selected randomly (age ranging from 25 to 40 years), both male and female in various positions and experiences. 100 questionnaire s were collected, 20 of which were not valid, leaving the remaining 80 questionnaires. The questionnaire consists of two sections:

- First section which contains personal and functional information related to the members sample.

- Second section which contains variables for studying organizational culture (variable Independent) and knowledge sharing as a dependent variable based on the most effecting factors in KS that was mentioned in the related works across Sudanese culture behaviors that support the KS process.

\subsection{Step Three: Proposing the KS framework Based on Results}

2.8.1 Results of Data Analysis

1. The current status of KS in Sudanese organizations 
The results of the analyzed data showed that there is an informal knowledge management system that supports sharing of knowledge and cooperation in dissemination of experience and skills between experienced old staff and the new staff. The most common knowledge sharing practices in the Sudanese organization are:

- Meetings: Periodic meetings between experienced senior employees and new or less experienced staff to determine the status of the organization and to advise them and respond to any inquiry

- Collaborating teams: This involves collaboration between older experience employees and new or less experience ones which enables managing and sharing of knowledge and experience effectively throughout the organization

- $\quad$ Enterprise Resource Planning (ERP) systems linking departments of the organization and ensuring the transfer of information accurately and correctly and in a timely manner

- Documentation Systems: Such as project progress reports and meeting documentation are stored within the system.

2. The Requirements for KS in Sudanese Organizations

The results also revealed some important requirements for implementing KS which can be summarized as:

- Management support in the form of staff appreciation, valuation and assessment, incentives, and the structure of authority and accountability have a major influence in the attitude towards knowledge sharing.

- Organizational culture was also found to play an important role in Knowledge Sharing. Internal culture that resists knowledge sharing represents a powerful obstacle that should be overcome in the application of knowledge management. Most of the staff admitted that organization should recognize the importance establishing a culture that promotes and encourage KS among staff

- The social relations, Communication and Collaboration between individuals within organizations had an impact on the ability to share knowledge since these social relations build trust between these individuals.

- Staff's Confidence and their positive attitude toward KS and its benefits play an important role in the success of KS process and increase the ability to share knowledge with others and thus reduce the cost of exchange.

- Most Sudanese organizations under study have IT infrastructure and ERP systems that link departments and facilitate the exchange of knowledge. These systems enable organization to collect information in a unified data repository and thus facilitate knowledge sharing and information exchange between different sections of the organization which in turn facilitate the sharing of knowledge in the short and long term and aid the process of decision making.

\subsubsection{The Proposed Framework of KS}

Implementation in Sudanese Organizations

Based on the results discussed earlier this study proposes a framework for the requirements of $\mathrm{KS}$ implementation in Sudanese Organizations. These requirements are listed below and are shown in Figure 6.

1. Management Support

2. Organizational Culture

3. Confidence and Trust

4. IT infrastructure and ERP Systems

\subsubsection{Expected Outcome of the Implementation} of the Proposed Framework

Enabling the concept of knowledge sharing based on the identified requirements has the following benefits:

- IT Infrastructure and KMSs Information Technology and KMS systems make all units of organizations integrated and connected and reduce time and cost of knowledge transfer and hence increase organizational productivity. They ensure sharing the right information at the right time and therefore enhance the process of decision making.

- $\quad$ Moving from traditional ERP systems to implementing ERP systems with KM capacity enables organizations to share and transfer knowledge effectively.

- Management Support and encouragement reduce employee turnover, build trust and confidence and connect the management with the rest of the staff

- Organizational culture (OC) that fosters collaboration and sharing of knowledge reduces the natural resistance of people and the existing culture toward change inside organizations.

- Confidance and Trust facilitate transactions and collaboration 


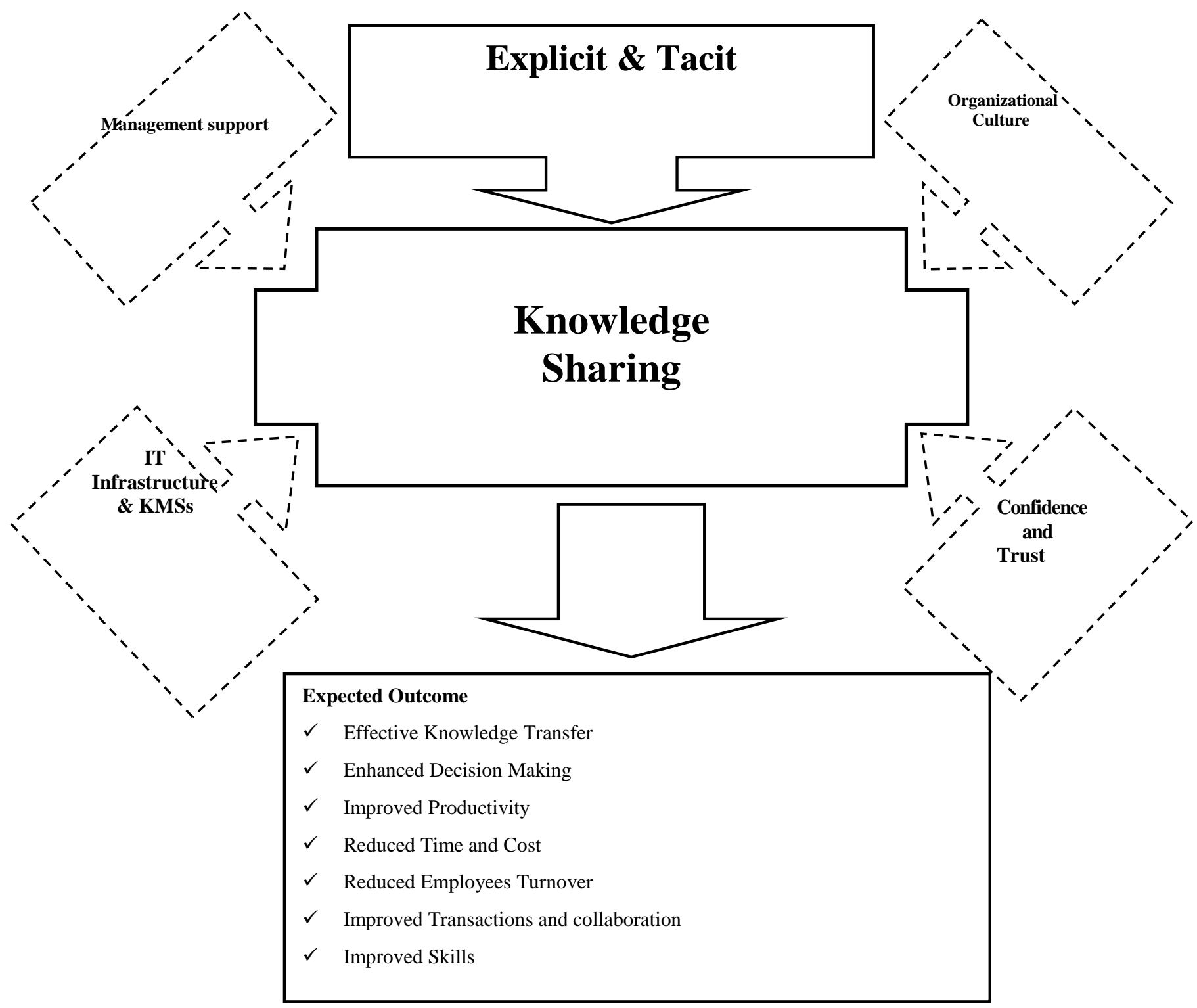

Fig2: the Proposed Framework of Using KS in Sudanese organizations

3 Obstacles of Knowledge Sharing in Sudanese Organizations.

The results showed some obstacles that most overcome in order to successfully implement KS. These are:

- A significant weakness of senior management in supporting knowledge sharing due to a gap between management and employees

- Weak communication between senior management and the staff.

- Lack of environment support for knowledge sharing.

- Lack of knowledge management Staff and/or knowledge management department.

\section{CONCLUSIONS}

This study investigated the current state of knowledge management and knowledge sharing in Sudanese organization and explored the factors and requirements that influence an effective knowledge sharing process in these organizations. Data was collected from organizations and analyzed. The results were used as the base for proposing a framework for the requirements of KS and identified Management Support, Organizational Culture, Confidence and Trust, and IT infrastructure and KMSs as the attributes that significantly influence KS in Sudanese organizations. The framework suggests that a strategy for implementing successful organizational KM initiatives requires understanding of the importance of KM, Management Support and leadership that build trust and confidence among employees, IT infrastructures and KMSs that sharing, utilizing and integrating knowledge, OC that fosters collaboration and reduces resistance are necessary requirements that needed to implement KS in Sudanese organizations.

\section{REFERENCES}

[1] Mohsen Z., Ali M, Jalal E. The Significance of Knowledge Management Systems at Financial Decision Making Process. International Journal of Business and Management Vol. 6, No. 8 (2011)

[2] Lundvall, B.Å., 1999. National business systems and national systems of innovation. International Studies of Management \& Organization, 29(2), pp.60-77. 
[3] Duhon, Bryant (1998), It's All in our Heads. Inform, September, 12 (8).

[4] Duffy, J., 2000. The KM technology infrastructure. Information Management, 34(2), p.62.

[5] King, W.R., 2000. Integrating knowledge management into IS strategy. Information Systems Management, 16, pp.7072.

[6] Hauer, M., 1999. Three thousand years of knowledge management: What can we learn from science? Information services \& use, 19(1), pp.37-44.

[7] Vail, E.F. (1999), "Mapping organisational knowledge", Knowle Duhon Management Review, Vol. 8, May/June, pp. 10-15.

[8] Girard, John P.; Girard, JoAnn L. (2015). Defining knowledge management: Toward an applied compendium. Online Journal of Applied Knowledge Management. 3 (1): 14.

[9] Davenport, Thomas H. (1994), Saving IT's Soul: Human Centered Information Management. Harvard Business Review, March-April, 72 (2) pp. 119-131.

[10] Yu T, Lu T and Liu T (2010), "Exploring Factors that Influence Knowledge Sharing Behavior Via Web Logs", Computers in Human Behavior, Vol. 26, No. 1, pp. 32-41.

[11] Senge, P.M. The Fifth Discipline: The Art and Practice of the Learning Organisation. New York: Doubleday, 1990.[70].

[12] Senge, P.M. Taking Personal Change Seriously: The Impact of Organizational Learning on Management Practice", Academy of Management Executive, Vol. 17, No. 2, pp. 47 50, 2003.

[13] Marquardt, M.J., 2002. Building the learning organization: Mastering the 5 elements for corporate learning. Nicholas Brealey Publishing.

[14] Ipe, M., 2003. Knowledge sharing in organizations: A conceptual framework. Human resource development review, 2(4), pp.337-359.
[15] Jones, M.C., Cline, M. and Ryan, S., 2004. Exploring knowledge sharing in ERP implementation: an organizational culture framework. Decision Support Systems, 41(2), pp.411-434.

[16] Goh, S.C., 2002. Managing effective knowledge transfer: an integrative framework and some practice implications. Journal of knowledge management, 6(1), pp.23-30.

[17] Huczynski, A., Buchanan, D., (2001), Organizational Behaviour -An Introductory Text, Prentice Hall, Harlow

[18] Bidokhti, H, (2000). Organizational culture, area of creating and symbols. Ravesh. 58, 6-13.

[19] De Long, D. W., \& Fahey, L. (2000). Diagnosing cultural barriers to knowledge management. Academy of Management Executive, 14(4), 113-127.

[20] Nonaka, I., Toyama, R. and Konno, N., 2000. SECI, Ba an d leadership: a unified model of dynamic knowledge creation. Long range planning, 33(1), pp.5-34.

[21] Zheng, W., Yang, B. \& McLean, G. N. (2010) Linking organizational culture, structure, strategy, and organizational effectiveness: Mediating role of knowledge management Journal of Business Research,63(7), 763-771.

[22] Ruppel, C. P. \& Harrington, S. J. (2001) Sharing knowledge through intranets: a study of organizational culture and intranet implementation. Professional Communication, IEEE Transactions on, 44(1), 37-52.

[23] Wang, S. \& Noe, R. A. (2010) Knowledge sharing: A review and directions for future research. Human Resource Management Review, 20(2), 115-131.

[24] Alavi, M. and Leidner, D.E., 2001. Knowledge management and knowledge management systems: Conceptual foundations and research issues. MIS quarterly, pp.107-136.

[25] Zahidul Islam1 Md, Sylvana Maheen Ahmed2, Ikramul Hasan2 and Sarwar Uddin Ahmed2. Organizational culture and knowledge sharing: Empirical evidence from service organizations African Journal of Business Management Vol. 5(14), pp. 5900-5909, 18 July, 2011 